\section{Commentary: Another variable in the puzzle}

\author{
Pierre-Emmanuel Noly, MD, and Michel Carrier, MD
}

The science of heart transplantation is well established, but donor and recipient selection and matching remains an art. On the donor side, age, female donor to male recipient, donor to recipient weight mismatch, predicted heart mass mismatch, cause of donor brain death, and total ischemic time are among the most commonly reported risk factors for primary graft failure and early recipient death. ${ }^{1,2}$ These are usually weighted according to the recipient's characteristics and surgical risk factors in the decision to undergo or withhold heart transplantation in a specific patient.

Tang and colleagues ${ }^{3}$ studied the effect of the relationship between donor ABO blood type and allograft ischemic time (IT) on recipient survival. Using data from 32,454 heart transplants included in the United Network for Organ Sharing database, the authors compared the incidence of primary graft dysfunction (PGD), chronic rejection, and survival between $\mathrm{O}$ and non-O donor blood groups. Patients were stratified according to ischemic time $(<4$ hours and $\geq 4$ hours). A propensity score-match analysis using logistic regression that included 24 variables was performed to compare $\mathrm{O}$ and non-O blood type donor hearts. The main findings of this study are: type-O blood group donor hearts in the IT $\geq 4$ hours group experienced inferior 15 -year survival when compared with non-O blood type donor hearts but not in the IT $<4$ hours group, O blood type donor hearts in the IT $\geq 4$ hours group had a $16.4 \%$ increase in mortality risk compared with non-O blood type donors, and this survival difference was explained by a greater incidence of death from PGD and chronic rejection.

\footnotetext{
From the Division of Cardiac Surgery, Montreal Heart Institute, University of Montreal, Montreal, Québec, Canada.

Disclosures: The authors reported no conflicts of interest.

The Journal policy requires editors and reviewers to disclose conflicts of interest and to decline handling or reviewing manuscripts for which they may have a conflict of interest. The editors and reviewers of this article have no conflicts of interest.

Received for publication Jan 12, 2021; revisions received Jan 12, 2021; accepted for publication Jan 13, 2021; available ahead of print Jan 20, 2021.

Address for reprints: Michel Carrier, MD, Department of Surgery, Montreal Heart Institute, University of Montreal, 5000 Belanger St, E, Montreal, Québec H1T1C8 Canada (E-mail: michel.carrier@icm-mhi.org).

J Thorac Cardiovasc Surg 2022;164:994-5

$0022-5223 / \$ 36.00$

Copyright (c) 2021 by The American Association for Thoracic Surgery

https://doi.org/10.1016/j.jtcvs.2021.01.042
}

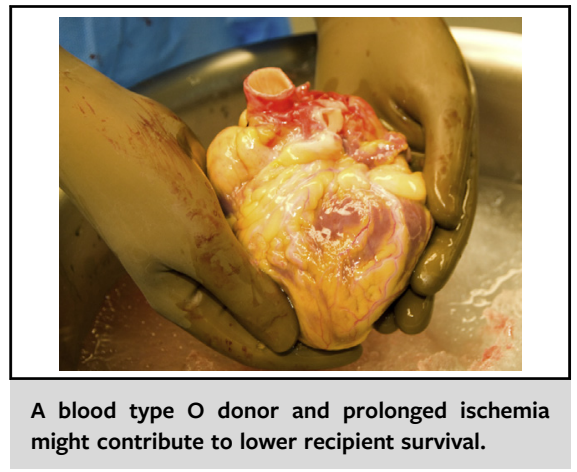

CENTRAL MESSAGE

Donor blood type $\bigcirc$ with longer

ischemic time might represent

an additional risk factor for pri-

mary graft dysfunction and

death.

This study confirms the findings of Jawitz and colleagues, ${ }^{4}$ who first showed that blood type O donor grafts were associated with decreased survival after heart transplant. Tang and colleagues ${ }^{3}$ give us a new, important perspective by suggesting the detrimental effect on survival of donor blood type $\mathrm{O}$ with prolonged IT in a large cohort. Recipients of $\mathrm{O}$ blood type donor hearts may be more susceptible to prolonged warm and cold ischemic preservation damage related to the production of disproportionate amounts of inflammatory mediators. This biological characteristic peculiar to blood type $\mathrm{O}$ may explain the greater rates of PGD, chronic allograft vasculopathy, and worse short- and long-term recipient survival. A large number of patients, the long-term follow-up, the transparency, and the quality of the propensity analysis are the strengths of this study.

We should also keep in mind several limitations. Propensity score-matching techniques are only able to balance the known confounders. Another main limitation of this study is the use of IT as a categorical variable instead of a continuous variable. An analysis to determine the cut-point in ischemic time that influence outcomes for the various $\mathrm{ABO}$ blood groups would be of great value.

Consistent with previous studies, ${ }^{5,6}$ ABO compatible versus identical matching was not a significant predictor of mortality. Based on the findings offered by Tang and colleagues, ${ }^{3}$ we may wonder whether we should continue to 
use $\mathrm{O}$ blood type donors for non-O recipients if IT is expected to last more than 4 hours.

Because blood type $\mathrm{O}$ donors represent half of the donor pool and because they are universal donors whose organs can be allocated to recipients with any blood type, these findings might have a tremendous influence on cardiac donor selection. As suggested by the authors, blood type $\mathrm{O}$ donors should be used with caution in clinical conditions with an expected prolonged allograft ischemic time. Further studies are needed to confirm these results and we look forward to seeing a complementary analysis using IT as a continuous variable.

\section{References}

1. Khush KK, Cherikh WS, Chambers DC, Harhay MO, Hayes D Jr, Hsich E, et al. The international thoracic organ transplant registry of the International Society for Heart and Lung Transplantation: 36th adult heart transplantation report - 2019; focus theme: donor and recipient size match. J Heart Lung Transplant. 2019;38: 1056-66.

2. Kobashigawa J, Zuckermann A, Macdonald P, Leprince P, Esmailian F, Luu M, et al. Report from a consensus conference on primary graft dysfunction after cardiac transplantation. J Heart Lung Transplant. 2014;33:327-40.

3. Tang PC, Haft JW, Lei I, Wang Z, Chen E, Abou El Ela A, et al. Impact of donor blood type on outcomes after prolonged allograft ischemic times. J Thorac Cardiovasc Surg. 2022;164:981-93.e8.

4. Jawitz OK, Jawitz N, Yuh DD, Bonde P. Impact of ABO compatibility on outcomes after heart transplantation in a national cohort during the past decade. $J$ Thorac Cardiovasc Surg. 2013;146:1239-45.

5. Ando M, Takeda K, Kurlansky PA, Garan AR, Topkara VK, Yuzefpolskaya M, et al. Association between recipient blood type and heart transplantation outcomes in the United States. J Heart Lung Transplant. 2020;39:363-70.

6. Khush KK, Potena L, Cherikh WS, Chambers DC, Harhay MO, Hayes D Jr, et al. The international thoracic organ transplant registry of the International Society for Heart and Lung Transplantation: 37th adult heart transplantation report-2020; focus on deceased donor characteristics. J Heart Lung Transplant. 2020;39: 1003-15.
See Article page 981.

\section{Commentary: Donor selection in heart transplantation: It's a match!}

\author{
Alvise Guariento, MD, ${ }^{\mathrm{a}}$ David Blitzer, MD, ${ }^{\mathrm{b}}$ and \\ Vladimiro Vida, $\mathrm{MD}, \mathrm{PhD}^{\mathrm{c}}$
}

In the field of heart transplantation, hyperacute rejection, commonly resulting from transplantation between a donor and recipient of different $\mathrm{ABO}$ blood groups, is a catastrophic complication and is ideally avoided by careful and deliberate blood group matching. Although blood group $\mathrm{O}$ donors are known as universal donors, transplantation of hearts from this blood group has been associated with reduced survival. ${ }^{1}$

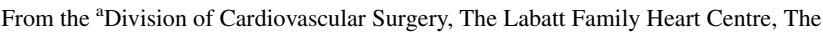
Hospital for Sick Children, University of Toronto, Toronto, Ontario, Canada; ${ }^{\mathrm{b}}$ Department of Surgery, Columbia University Medical Center, New York, NY; and ${ }^{\mathrm{C}}$ Paediatric and Congenital Cardiac Surgery Unit, Department of Cardiac, Thoracic and Vascular Sciences, University of Padua, Padua, Italy.

Disclosures: The authors reported no conflicts of interest.

The Journal policy requires editors and reviewers to disclose conflicts of interest and to decline handling or reviewing manuscripts for which they may have a conflict of interest. The editors and reviewers of this article have no conflicts of interest.

Received for publication Jan 4, 2021; revisions received Jan 4, 2021; accepted for publication Jan 5, 2021; available ahead of print Jan 19, 2021.

Address for reprints: Alvise Guariento, MD, Division of Cardiovascular Surgery, The Hospital for Sick Children, 555 University Ave, Toronto, Ontario, Canada, M5G 1X8 (E-mail: alvise.guariento@sickkids.ca).

J Thorac Cardiovasc Surg 2022;164:995-6

$0022-5223 / \$ 36.00$

Copyright (c) 2021 by The American Association for Thoracic Surgery

https://doi.org/10.1016/j.jtcvs.2021.01.012
}

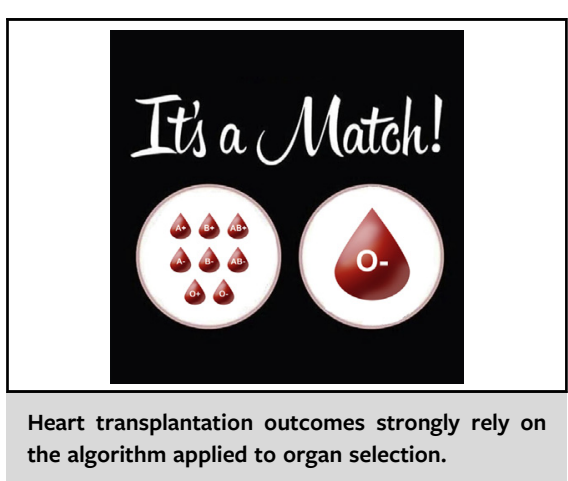

CENTRAL MESSAGE

A more in-depth study of donorrecipient blood groupdependent immune mechanisms in heart transplantation is needed.

In the current issue of the Journal, Tang and colleagues ${ }^{2}$ investigated the impact of organ ischemic time on donorrecipient blood group compatibility. In their paper, the authors elegantly analyzed data from the United Network for Organ Sharing database with a propensity score-matching technique, thus accounting for covariates that may otherwise bias the results. Their conclusions showed that transplantation with type $\mathrm{O}$ donor hearts and an ischemia time $>4$ hours may lead to lower survival due to primary 